\title{
Population pharmacokinetics of tacrolimus in pediatric patients with systemic-onset juvenile idiopathic arthritis: Initial dosage recommendations
}

\author{
DONGDONG WANG ${ }^{1 *}, \mathrm{XIAO} \mathrm{CHEN}^{1 *}, \mathrm{HONG} \mathrm{XU}^{2}$ and ZHIPING LI ${ }^{1}$ \\ Departments of ${ }^{1}$ Pharmacy and ${ }^{2}$ Nephrology and Rheumatology, Children's Hospital of Fudan University, \\ Shanghai 201102, P.R. China
}

Received May 6, 2019; Accepted October 4, 2019

DOI: $10.3892 /$ etm.2019.8129

\begin{abstract}
Pediatric patients with systemic-onset juvenile idiopathic arthritis (SOJIA) may be treated with tacrolimus. However, the therapeutic range for tacrolimus is narrow with considerable inter- and intra-individual variability, making it difficult to formulate an ideal dosage regimen for personalized treatment. The purpose of the present study was to set up a population pharmacokinetics (PPK) model of tacrolimus treatment for SOJIA to determine the optimal initial dosage. Patients with SOJIA were analyzed using non-linear mixed-effects modeling. Different regimens were analyzed using Monte Carlo simulation with concentration profiles. A first-order absorption and elimination one-compartment model was selected as the most appropriate model for SOJIA. Based on initial dosage recommendations, the regimen of $0.5 \mathrm{mg}$ every $24 \mathrm{~h}$ (q24h) appeared to be most suitable for subjects with a body weight of $5 \mathrm{~kg}$, while the $0.5 \mathrm{mg}$ q12h regimen was most suitable for subjects with a body weight of $15-25 \mathrm{~kg}$, the $1 / 0.5 \mathrm{mg}$ q $24 \mathrm{~h}$ regimen was appropriate for the $26-35 \mathrm{~kg}$ group and the $1 \mathrm{mg} \mathrm{q} 12 \mathrm{~h}$ regimen was suitable for the subjects with a body weight of $36-50 \mathrm{~kg}$. To the best of our knowledge, the present study established the first PPK model of tacrolimus treatment that may be used for the selection of the initial dose based on body weight of pediatric patients with SOJIA.
\end{abstract}

Correspondence to: Professor Hong $\mathrm{Xu}$, Department of Nephrology and Rheumatology, Children's Hospital of Fudan University, 399 Wanyuan Road, Shanghai 201102, P.R. China E-mail: hxu@shmu.edu.cn

Professor Zhiping Li, Department of Pharmacy, Children's Hospital of Fudan University, 399 Wanyuan Road, Shanghai 201102, P.R. China

E-mail: zplifudan@126.com

*Contributed equally

Key words: personalized medicine, population pharmacokinetics, systemic-onset juvenile idiopathic arthritis, tacrolimus, initial dosage recommendations

\section{Introduction}

Systemic-onset juvenile idiopathic arthritis (SOJIA) is a serious type of juvenile arthritis (1). It is driven by continuous activation of innate immune pathways producing pro-inflammatory cytokines (2).

Treatment with tacrolimus may suppress early activation of interleukin (IL)-2 gene transcription and inhibit the production of tumor necrosis factor- $\alpha$ (TNF- $\alpha$ ), IL- $1 \beta$ and IL- 6 during T-cell activation $(3,4)$. Tacrolimus treatment in patients with SOJIA has been reported previously (5-8). However, as an immunosuppressive agent, the therapeutic range of tacrolimus is narrow, with considerable inter- and intra-individual variability $(9,10)$.

Population pharmacokinetics (PPK) may be used to acquire PK information from sparse population data. Furthermore, PPK may differentiate between inter-individual and intra-individual variability and has considerable power to uncover the effects of confounding factors on PK behavior and to ensure that a treatment is suitable for personalized clinical therapy (11). In previous studies, PPK models of tacrolimus were set up among different populations (12-24). However, the PPK model of tacrolimus treatment in patients with SOJIA has remained to be established. The aim of the present study was to set up a tacrolimus PPK model in patients with SOJIA and to formulate initial dosage recommendations for personalized treatment.

\section{Materials and methods}

Patient data. Data from Chinese patients with SOJIA who attended the Children's Hospital of Fudan University (Shanghai, China) between January 2014 and December 2017 were retrospectively collected. The inclusion criteria were as follows: i) Pediatric patients with SOJIA (aged $<16$ years); ii) treatment with tacrolimus; iii) tacrolimus concentrations were routinely tested by therapeutic drug monitoring (TDM). Subjects with other concurrent serious clinical conditions were excluded (e.g. liver, kidney or bone marrow transplant). A schematic depicting the recruitment of the patients is provided in Fig. 1. Relevant clinical information and data on drug concentrations were gathered from medical records and TDM records, respectively. Demographic data of the patients and concomitant drugs were used as potential covariates to be analyzed in the current PPK 
model. The present study was a retrospective study and was approved by the ethics committee of the Children's Hospital of Fudan University (Shanghai, China) without the requirement for written informed consent.

Drug administration and analytical method. Oral tacrolimus dose adjustment was based on safety and effectiveness, along with the drug trough concentration from TDM. The whole-blood concentration of tacrolimus was analyzed using the Emit ${ }^{\circledR} 2000$ Tacrolimus assay (Siemens Healthcare Diagnostics Inc.) according to the manufacturer's protocol.

PPK modeling. Patient data were analyzed using the nonlinear mixed-effects model (NONMEM, edition 7; ICON Development Solutions). PK parameters and their variability were estimated using the first-order conditional estimation method with interaction. The absorption phase was described using a first-order absorption and elimination one-compartment model. The PK parameters included apparent oral clearance $(\mathrm{CL} / \mathrm{F})$ and apparent volume of distribution (V/F). F was the bioavailability. The absorption rate constant (Ka) was set at 4.48/h (15).

Random-effects model. Inter-individual variability was analyzed using an exponential error model, as presented in equation i:

$$
\text { (i) } P_{j}=T V(P) \times \exp \left(\eta_{j}\right)
$$

$\mathrm{P}_{\mathrm{j}}$ is the value of the individual parameter. TV(P) is the parameter of the typical value. The individual deviation is represented by $\eta_{\mathrm{j}}$, which is a symmetrically distributed, zero-mean random variable with variance terms.

The random residual variability was described using equation ii:

$$
\text { (ii) } \mathrm{Y}=\mathrm{IPRED}+\varepsilon
$$

$\mathrm{Y}$ is the concentration observed and IPRED represents the individual predicted concentration. The variation is represented by $\varepsilon$, which is a symmetrically distributed, zero-mean random variable with variance terms.

Covariate model. Weight and PK parameters were modeled using equation iii:

$$
\text { (iii) } \mathrm{P}_{\mathrm{j}}=\mathrm{P}_{\text {norm }} \mathrm{x}\left(\text { Weight }_{\mathrm{j}} / \text { Weight }_{\text {norm }}\right)^{\mathrm{COE}}
$$

$P_{j}$ represents the PK parameter of the $j$-th individual, Weight is the Weight of the $\mathrm{j}$-th individual and $\mathrm{P}_{\text {norm }}$ is the parameter of an individual with a normal Weight (Weight ${ }_{\text {norm }}$ ) of $70 \mathrm{~kg}$. The COE is the allometric coefficient: 0.75 for the CL/F and 1 for the $\mathrm{V} / \mathrm{F}(25)$.

Continuous covariates and categorical covariates were used to describe the correlation between PK parameters using equations iv and v:

(iv) $\mathrm{P}_{\mathrm{j}}=\mathrm{TV}(\mathrm{P}) \times\left(\operatorname{Cov}_{\mathrm{j}} / \operatorname{Cov}_{\mathrm{med}}\right)^{\theta}$

(v) $P_{j}=T V(P) \times\left(1+\theta \times \operatorname{Cov}_{j}\right)$

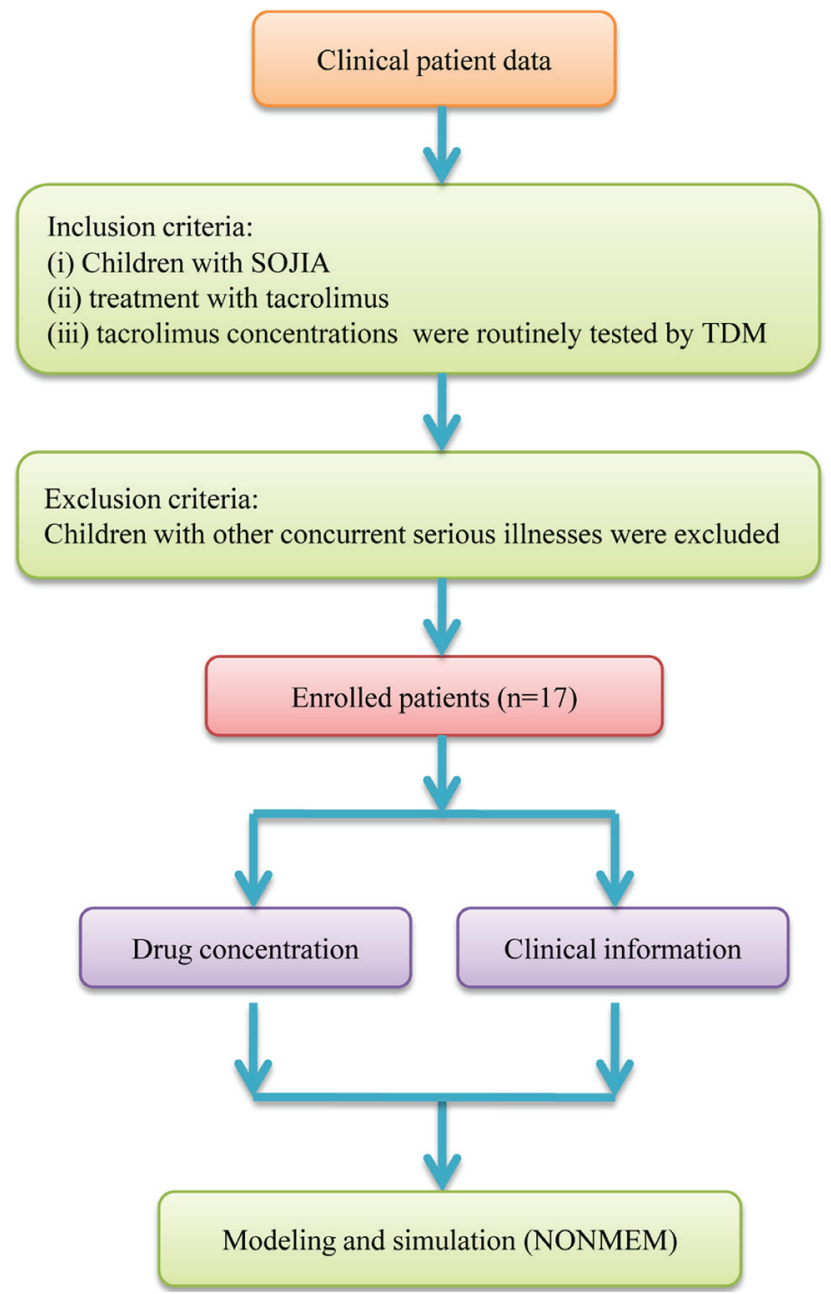

Figure 1. Schematic of patient recruitment. SOJIA, systemic-onset juvenile idiopathic arthritis; TDM, therapeutic drug monitoring; NONMEM, nonlinear mixed-effects model.

$\mathrm{P}_{\mathrm{j}}$ and $\mathrm{TV}(\mathrm{P})$ are the individual parameter value and typical parameter value, respectively. $\operatorname{Cov}_{\mathrm{j}}$ is the covariate of the $\mathrm{j}$-th individual and $\theta$ is the parameter to be estimated. $\operatorname{Cov}_{\text {med }}$ is the population median for the covariate.

This stepwise protocol was used to build the covariate model. The likelihood ratio test was used to compare hierarchical models. The covariate model was established in a stepwise manner, using the forward inclusion, backward elimination method $(11,21,24,26,27)$. Changes in objective function values (OFV) were performed using covariate inclusions and a decrease of OFV $>3.84(\mathrm{P}<0.05)$ was considered sufficient for inclusion in the base model $(11,21,24,26,27)$. After establishing a full regression model, the model was further assessed by eliminating covariates from each PK parameter one-by-one to obtain the final model. An increase in OFV $>6.64(\mathrm{P}<0.01)$ was considered sufficient for significance in the final model $(11,21,24,26,27)$. This statistical method and its description have been published in numerous similar studies and may be considered as a fixed and applicable statistical method for PPK analysis $(11,21,24,26,27)$.

Model validation. The stability and reliability of the final parameter estimates were evaluated using the internal 
Table I. Demographic data of the patients.

\begin{tabular}{lcr}
\hline Characteristic & Mean \pm SD & Median (range) \\
\hline Age (years) & $8.23 \pm 3.30$ & $9.50(3.20-14.60)$ \\
Weight $(\mathrm{kg})$ & $29.83 \pm 10.66$ & $33.60(13.50-46.00)$ \\
Duration of treatment with tacrolimus (days) & $190.59 \pm 169.57$ & $67.00(5.00-535.00)$ \\
Daily dose of tacrolimus (mg) & $1.66 \pm 0.71$ & $1.50(1.00-4.00)$ \\
Alanine transaminase (IU/l) & $28.56 \pm 60.24$ & $12.00(2.00-458.00)$ \\
Aspartate transaminase (IU/l) & $21.01 \pm 26.82$ & $15.00(7.00-235.00)$ \\
Creatinine $(\mu$ mol/l) & $35.36 \pm 10.32$ & $35.50(19.00-59.00)$ \\
Hematocrit $(\%)$ & $37.35 \pm 3.43$ & $37.45(30.30-44.40)$ \\
Hemoglobin $(\mathrm{g} / \mathrm{l})$ & $121.59 \pm 13.23$ & $124.00(90.20-152.00)$ \\
Mean corpuscular hemoglobin $(\mathrm{pg})$ & $27.13 \pm 2.01$ & $27.00(21.00-31.00)$ \\
Mean corpuscular hemoglobin concentration $(\mathrm{g} / \mathrm{l})$ & $324.58 \pm 15.22$ & $323.00(285.00-358.00)$
\end{tabular}

SD, standard deviation.

validation method of bootstrap, which was produced using repeated random sampling, with replacement from the original data. The process was performed using the Wings package for NONMEM software and was repeated 1,000 times with different random draws. The median values and $2.5-97.5 \%$ percentile parameters from the bootstrap results were compared with the final PK parameters. Visual inspection of routine diagnostic plots along with prediction-corrected visual predictive check (VPC) plots were used to assess the final model.

Simulation of initial dosage recommendations. Monte Carlo simulation is an approach used to determine probability of target (28) and has been applied to determine the most suitable drug administration $(22,26)$. In the present study, it was used to investigate the influence of covariates on the probability to achieve the target concentrations. A previous study reported that for safety reasons, the lower concentration for tacrolimus treatment for SOJIA was $1.7 \mathrm{ng} / \mathrm{ml}$ and the upper concentration was $5 \mathrm{ng} / \mathrm{ml}$ (7). Therefore, the probability to achieve 1.7 and $5 \mathrm{ng} / \mathrm{ml}$ concentration thresholds based on the established model without the combination with other drugs was estimated. Simulation was performed for each of the nine weight groups $(5,15,20,25,30,35,40,45$ and $50 \mathrm{~kg})$ and four dosing regimens [0.5 mg once every $24 \mathrm{~h}$ (q24h), $0.5 \mathrm{mg}$ q12h, $1 / 0.5 \mathrm{mg}$ q24h and $1 \mathrm{mg} \mathrm{q} 12 \mathrm{~h}$ ] using 1,000 virtual patients with SOJIA.

\section{Results}

Data collection. Data from 17 Chinese patients with SOJIA (8 males and 9 females), aged 9.50 (3.20-14.60) years, were collected to build the population model. A total of 86 concentrations in the range of 1.3 to $9.2 \mathrm{ng} / \mathrm{ml}$ were used. Patient information and drug combinations are presented in Tables I and II.

Modeling. The first-order absorption and elimination one-compartment model was identified to fit the dataset. PK parameters from the final covariate models were as follows in equations vi and vii:

vi) $\mathrm{CL} / \mathrm{F}=29.7 \mathrm{x}(\text { weight/70) })^{0.75} \mathrm{x}(1-0.362 \mathrm{x}$ omeprazole $) \mathrm{x}$ (1-0.322 x loratadine $) \times(1-0.307 \times$ diltiazem $)$

vii) $\mathrm{V} / \mathrm{F}=1,120 \times($ weight $/ 70)$

When patients were co-administered omeprazole, loratadine or diltiazem, the value of each was 1 ; otherwise, the value was 0 . All weights in equations vi and vii were measured in $\mathrm{kg}$.

Validation. The visual inspection of routine diagnostic plots is presented in Fig. 2 and the parameter estimates from the final model and bootstrap validation are presented in Table III. From 1,000 bootstrap runs, 988 runs were successfully minimized. Using Table III, the parameter estimate median values of bootstraps were found to be similar to the respective values determined with the final model, indicating that the final PPK model was accurate and reliable. The VPC plots for the final model (Fig. 3) demonstrate that most of the measured concentration data were included in the $95 \%$ prediction intervals of the simulation data, suggesting that the final PPK model is able to predict concentrations effectively.

Simulation. In the present study, the initial tacrolimus dose without drug combination was predicted. In clinical practice, combination therapy is not common at the time of initial administration. Therefore, the probability to achieve the target concentrations based on the established model without any combined drugs was estimated. The predicted median, along with the $2.5-97.5 \%$ percentile parameters and the probability of achieving the target concentration were presented in Table IV. According to the simulation dataset, the $0.5 \mathrm{mg}$ q24h regimen appeared to be most suitable for pediatric patients with $5 \mathrm{~kg}$ body weight, the $0.5 \mathrm{mg} \mathrm{q} 12 \mathrm{~h}$ regimen was appropriate for patients with $15-25 \mathrm{~kg}$ body weight, the $1 / 0.5 \mathrm{mg} \mathrm{q} 24 \mathrm{~h}$ regimen was most suitable for subjects with a body weight of 
Table II. Drug combinations with tacrolimus.

Drug/category

Ranitidine
0
1

Hydroxychloroquine

0

1

Ceftazidime

0

1

Cefmetazole

0

1

Ceftriaxone

0

1

Cefprozil

0

1

Cefixime

0

1

Cefdinir

0

1

Azithromycin

0

1

Methylprednisolone

0

1

Mycophenolate mofetil

0

1

Prednisone

0

1

Oxcarbazepine

0

1

Levetiracetam

0

1

Methotrexate

0

1

Omeprazole

0

1

Diltiazem

0

1

Table II. Continued.

\begin{tabular}{lr}
\hline Drug/category & $\mathrm{N}$ \\
\hline Felodipine & \\
0 & 16 \\
1 & 1 \\
Montelukast & \\
0 & 16 \\
1 & 1 \\
Aspirin & \\
0 & 15 \\
1 & 2 \\
Loratadine & \\
0 & 12 \\
1 & 5
\end{tabular}

16

Categories: 0, without drug; 1 , with drug. N, number of patients.

13

4

14

3

11

6

15
26-35 $\mathrm{kg}$ and the $1 \mathrm{mg}$ q12h regimen was fit for the group with a body weight of $36-50 \mathrm{~kg}$.

\section{Discussion}

To control SOJIA disease, a number of patients require long-term corticosteroid treatment (5). However, prolonged and repeated steroid treatment increases the risk of adverse reactions, including obesity, cushingoid appearance, hypertension, growth retardation, osteoporosis, infections and psychological problems (29). Thus, a safe and effective therapeutic method to treat patients with SOJIA remains to be explored (30).

Recent studies revealed the beneficial impact of suppressing IL-6 and other pathogenic pro-inflammatory cytokines for controlling SOJIA (30-32). Tacrolimus potently suppresses the production of TNF- $\alpha$, IL-1 $\beta$ and IL- 6 through T-cell activation $(4,33)$, and it has therefore been administered to patients with SOJIA (5-7).

However, the therapeutic range of tacrolimus is narrow, with considerable inter-individual and intra-individual variability $(9,10)$. Thus, it is necessary to build a tacrolimus PPK model for patients with SOJIA and to formulate initial dosage recommendations for personalized treatment.

To the best of our knowledge, the present study was the first to provide a PPK model of tacrolimus for patients with SOJIA. The PPK model was established for SOJIA patients by using a population modeling method. The approach was necessary, as logistic and ethical restrictions prohibit excessive blood sampling when studying pediatric patients (34). The tacrolimus PPK model is able to predict the PK process in patients with SOJIA and it therefore has important clinical value.

In the present study, the first-order absorption and elimination one-compartment model fitted the dataset, as all of the tacrolimus concentrations were trough concentrations and the Ka was fixed at a value from the literature of $4.48 / \mathrm{h}$ (15). It was not possible to estimate the area under the curve, minimum concentration and maximum concentration of tacrolimus, as the drug was orally administered and 
Table III. Parameter estimates of final model and bootstrap validation.

\begin{tabular}{|c|c|c|c|c|c|}
\hline \multirow[b]{2}{*}{ Parameter } & \multirow[b]{2}{*}{ Estimate } & \multirow[b]{2}{*}{$\mathrm{SE}(\%)$} & \multicolumn{2}{|c|}{ Bootstrap } & \multirow[b]{2}{*}{ Bias $(\%)$} \\
\hline & & & Median & $95 \% \mathrm{CI}$ & \\
\hline $\mathrm{CL} / \mathrm{F}(\mathrm{l} / \mathrm{h})$ & 29.700 & 9.300 & 29.800 & $(24.300,36.400)$ & 0.340 \\
\hline $\mathrm{V} / \mathrm{F}(1)$ & 1120.000 & 27.900 & 1120.000 & $(604.000,2188.000)$ & 0 \\
\hline $\mathrm{Ka}(1 / \mathrm{h})$ & 4.480 (fixed) & - & - & - & - \\
\hline$\theta_{\text {omeprazole }}$ & -0.362 & 16.800 & -0.371 & $(-0.499,-0.192)$ & 2.490 \\
\hline$\theta_{\text {loratadine }}$ & -0.322 & 23.800 & -0.326 & $(-0.462,-0.081)$ & 1.240 \\
\hline$\theta_{\text {diltiazem }}$ & -0.307 & 34.200 & -0.307 & $(-0.454,-0.006)$ & 0 \\
\hline$\omega_{\mathrm{CL} / \mathrm{F}}$ & 0.265 & 18.400 & 0.243 & $(0.129,0.352)$ & -8.300 \\
\hline$\sigma_{1}$ & 1.229 & 5.100 & 1.200 & $(1.040,1.326)$ & -2.360 \\
\hline
\end{tabular}

95\% CI was displayed as the 2.5th, 97.5th percentile of bootstrap estimates. SE, standard error; CL/F, apparent oral clearance (1/h); V/F, apparent volume of distribution (1); Ka, absorption rate constant $(1 / \mathrm{h}) ; \theta_{\text {omeprazole }}$, coefficient of omeprazole; $\theta_{\text {loratadine }}$, coefficient of loratadine; $\theta_{\text {diltiazem }}$, coefficient of diltiazem; $\omega_{\mathrm{CL} / \mathrm{F}}$, inter-individual variability of $\mathrm{CL} / \mathrm{F} ; \sigma_{1}$, residual variability, additive error. Bias, prediction error, calculated as Bias $=($ Median-Estimate $) /$ Estimate $\times 100 \%$.
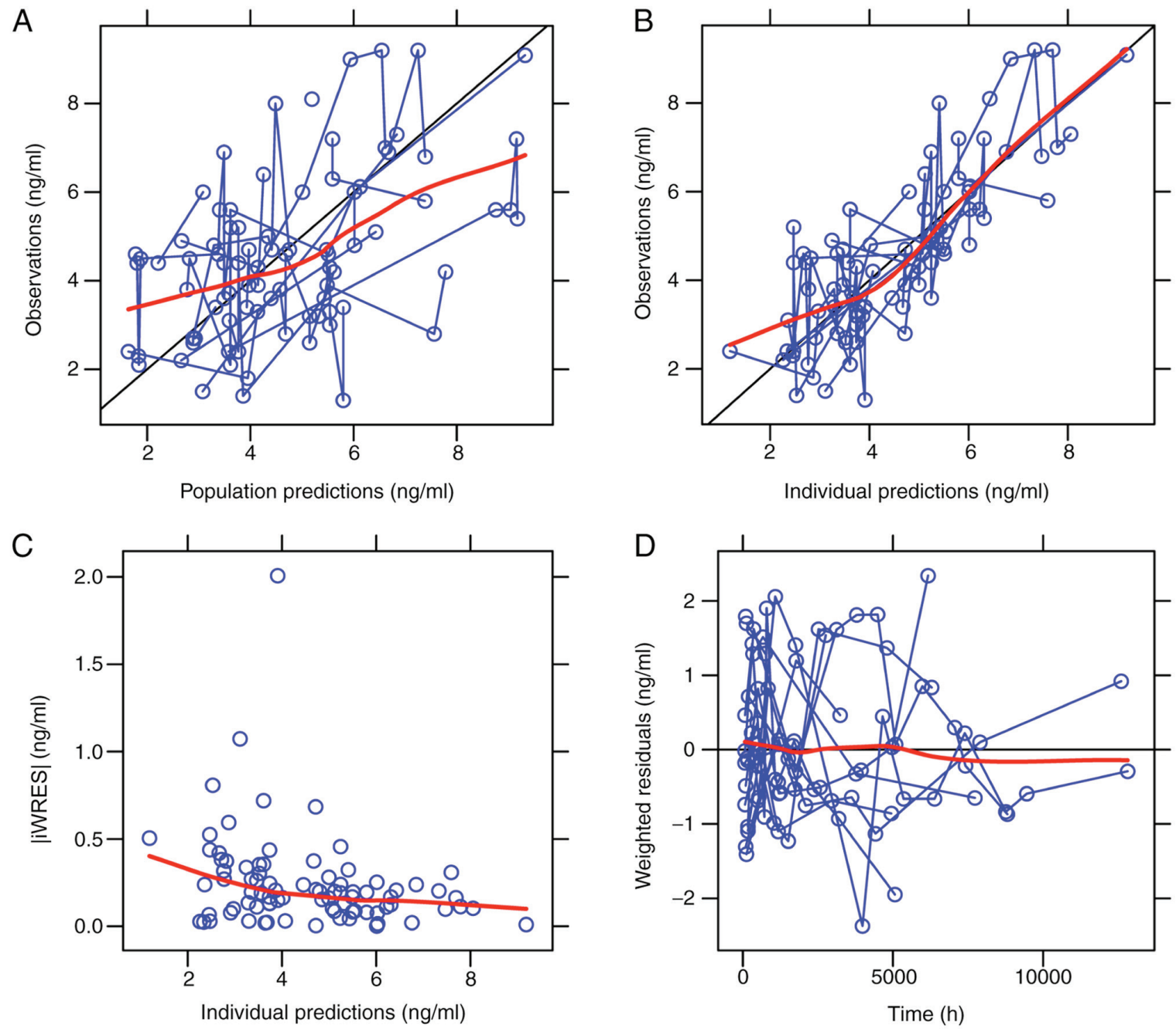

Figure 2. Visual inspection of routine diagnostic plots. (A) Observations vs. population predictions of tacrolimus blood concentrations. (B) Observations vs. individual predictions of tacrolimus blood concentrations. For (A) and (B), black solid lines represent the line of unity (the $y=x$ line, where predications match observed values), and the red smooth line represents the trend of the data. Hence, the closer the red smooth line is to the black solid line, the more predictive the model is. (C) liWRESI vs. individual predictions. liWRESI is the difference between the individual predictions and the observed tacrolimus blood concentrations. (D) weighted residuals vs. the time of tacrolimus blood concentration. black solid line represents the line of unity (the $y=0$ line). For (C) and (D), the red smooth line represents the trend of the data, therefore the closer the red smooth line is to the line of unity (the $y=0$ line), the more predictive the model is. liWRESI, individual weighted residuals. 


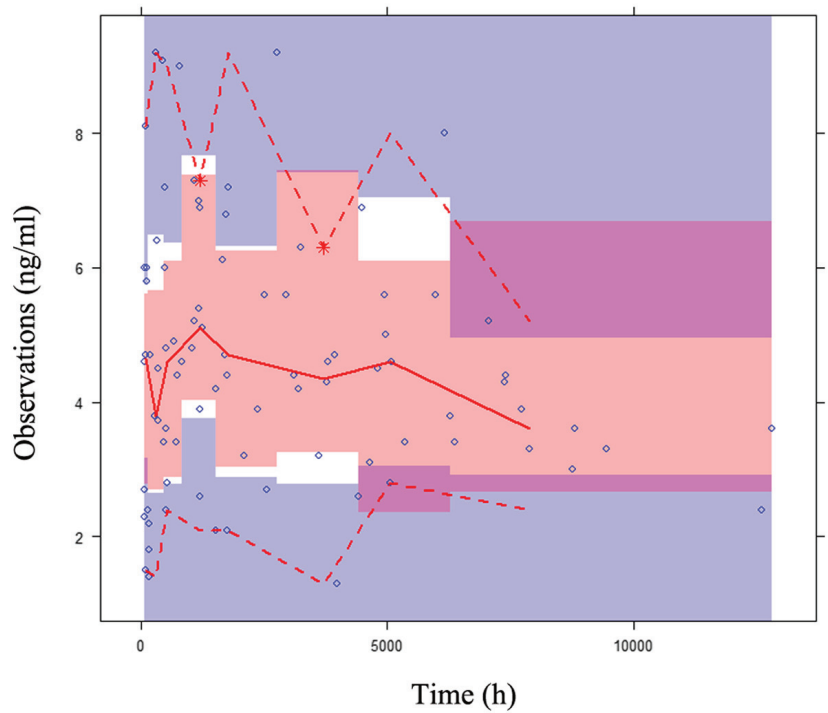

Figure 3. Prediction-corrected visual predictive check for the final model. The middle solid line represents the median of the prediction-corrected concentrations. The lower and upper dashed lines are the 2.5 and 97.5th percentiles of the prediction-corrected concentrations, respectively. The data-points indicate the measured concentrations. Theoretically, inclusion of the measured concentration in the $95 \%$ confidence interval of predicted values indicates good predictability of the model. Pink areas indicate the confidence interval of the middle solid line, purple areas indicate the confidence interval of the lower and upper dashed lines.

tacrolimus concentration data were insufficient. The typical $\mathrm{CL} / \mathrm{F}$ and $\mathrm{V} / \mathrm{F}$ values of the final tacrolimus PPK model were 29.7 1/h and 1,120 1. In the present PPK model, drug combinations were used as categorical variables. The present study also tested the influence of the following various covariates on different parameters: Weight, omeprazole, loratadine and diltiazem on $\mathrm{CL} / \mathrm{F}$, as well as Weight on V/F. Numerous studies have determined a non-linear association between drug clearance and body weight in pediatric patients, and it may be well described with allometric scaling using a coefficient of 0.75 for clearance and 1 for volume $(25,26,35,36)$. Body weight is the most important predictor of clearance and volume in pediatric patients with maturation of elimination processes (35), and is also considered to be the primary factor determining clearance and volume based on the theory explaining the link between mass, function and structure; this theory is valid across numerous orders of magnitude of body weight (37). Important factors that also impacted tacrolimus clearance were omeprazole, loratadine and diltiazem, possibly due to tacrolimus being a substrate of the cytochrome P450 3A (CYP3A) enzyme (38), and omeprazole and diltiazem inhibit CYP3A activity. In addition, loratadine is a CYP3A substrate that is able to compete with tacrolimus for the binding site on the enzyme and lead to a decrease in tacrolimus clearance. Thus, concomitant medication with omeprazole, loratadine or diltiazem may reduce tacrolimus clearance in patients with SOJIA.

In terms of model application, Monte Carlo simulations based on the established model were used to investigate the influence of covariates on the probability to achieve the target concentration. The probability to achieve 1.7 and $5 \mathrm{ng} / \mathrm{ml}$ concentration thresholds based on the established model without 
drug combinations was estimated. In addition, it appears that IL-6 is a marker of pharmacodynamics of tacrolimus (8). In future studies by our group, a population pharmacodynamics model will be built to analyze the association between drug exposure and IL-6.

In conclusion, to the best of our knowledge, the present study provided the first PPK model of tacrolimus in patients with SOJIA, and may be used for precision therapy in pediatric patients. A large external evaluation of this model will be performed in future studies.

\section{Acknowledgements}

Not applicable.

\section{Funding}

The present study was supported by the Clinical Pharmacy Key Specialty Construction Project of Shanghai (grant no. YZ2017/5), Important Weak Subject Construction Project of Shanghai (grant no. 2016ZB0305), the Scientific Research Project of Science and Technology Commission of Shanghai Municipality (grant no. 18DZ1910604) and the Fudan University Hospital Management Construction Project (Fudan medical administration 2018).

\section{Availability of data and materials}

The datasets used and/or analyzed during the present study are available from the corresponding author on reasonable request.

\section{Authors' contributions}

ZL and HX conceived and designed the study. DW and XC collected and analyzed the data. DW and XC wrote the manuscript. All authors read and approved the final manuscript.

\section{Ethics approval and consent to participate}

The study was approved by the Research Ethics Committee of the Children's Hospital of Fudan University (Shanghai, China).

\section{Patient consent for publication}

Not applicable.

\section{Competing interests}

The authors declare that they have no competing interests.

\section{References}

1. Schulert GS, Minoia F, Bohnsack J, Cron RQ, Hashad S, KonÉ-Paut I, Kostik M, Lovell D, Maritsi D, Nigrovic PA, et al: Effect of biologic therapy on clinical and laboratory features of macrophage activation syndrome associated with systemic juvenile idiopathic arthritis. Arthritis Care Res (Hoboken) 70 409-419, 2018.

2. Cimaz R: Systemic-onset juvenile idiopathic arthritis. Autoimmun Rev 15: 931-934, 2016.

3. Kawai $\mathrm{S}$ and Yamamoto K: Safety of tacrolimus, an immunosuppressive agent, in the treatment of rheumatoid arthritis in elderly patients. Rheumatology (Oxford) 45: 441-444, 2006.
4. Kondo H, Abe T, Hashimoto H, Uchida S, Irimajiri S, Hara M and Sugawara S: Efficacy and safety of tacrolimus (FK506) in treatment of rheumatoid arthritis: A randomized, double blind, placebo controlled dose-finding study. J Rheumatol 31: 243-251, 2004.

5. Chandrasekhara PK, Jayachandran NV, Thomas J, Agrawal S and Narsimulu G: Successful treatment of pyoderma gangrenosum associated with juvenile idiopathic arthritis with a combination of topical tacrolimus and oral prednisolone. Clin Rheumatol 28: 489-490, 2009

6. Shimizu M, Ueno K, Ishikawa S, Tokuhisa Y, Inoue $\mathrm{N}$ and Yachie A: Treatment of refractory polyarticular juvenile idiopathic arthritis with tacrolimus. Rheumatology (Oxford) 53: 2120-2122, 2014

7. Tanaka H, Tsugawa K, Suzuki K, Oki ES, Nonaka K, Kimura S and Ito E: Treatment of difficult cases of systemic-onset juvenile idiopathic arthritis with tacrolimus. Eur J Pediatr 166: 1053-1055, 2007.

8. Wang D, Chen $X$ and Li Z: Treatment of patients with systemic-onset juvenile idiopathic arthritis with tacrolimus. Exp Ther Med 17: 2305-2309, 2019.

9. Jusko WJ, Thomson AW, Fung J, McMaster P, Wong SH, Zylber-Katz E, Christians U, Winkler M, Fitzsimmons WE, Lieberman R, et al: Consensus document: Therapeutic monitoring of tacrolimus (FK-506). Ther Drug Monit 17: 606-614, 1995.

10. Venkataramanan R, Swaminathan A, Prasad T, Jain A, Zuckerman S, Warty V, McMichael J, Lever J, Burckart G and Starzl T: Clinical pharmacokinetics of tacrolimus. Clin Pharmacokinet 29: 404-430, 1995.

11. Vadcharavivad S, Praisuwan S, Techawathanawanna N, Treyaprasert W and Avihingsanon Y: Population pharmacokinetics of tacrolimus in Thai kidney transplant patients: Comparison with similar data from other populations. J Clin Pharm Ther 41: 310-328, 2016.

12. Monchaud C, de Winter BC, Knoop C, Estenne M, Reynaud-Gaubert M, Pison C, Stern M, Kessler R, Guillemain R, Marquet P and Rousseau A: Population pharmacokinetic modelling and design of a Bayesian estimator for therapeutic drug monitoring of tacrolimus in lung transplantation. Clin Pharmacokinet 51: 175-186, 2012.

13. Wallin JE, Friberg LE, Fasth A and Staatz CE: Population pharmacokinetics of tacrolimus in pediatric hematopoietic stem cell transplant recipients: New initial dosage suggestions and a model-based dosage adjustment tool. Ther Drug Monit 31: 457-466, 2009.

14. Zhu L, Yang J, Zhang Y, Jing Y, Zhang Y and Li G: Effects of CYP3A5 genotypes, ABCB1 C3435T and G2677T/A polymorphism on pharmacokinetics of Tacrolimus in Chinese adult liver transplant patients. Xenobiotica 45: 840-846, 2015.

15. Yang JW, Liao SS, Zhu LQ, Zhao Y, Zhang Y, Sun XY, Rao W, Qu W, Li WZ and Sun LY: Population pharmacokinetic analysis of tacrolimus early after Chinese pediatric liver transplantation. Int J Clin Pharmacol Ther 53: 75-83, 2015.

16. Musuamba FT, Guy-Viterbo V, Reding R, Verbeeck RK and Wallemacq P: Population pharmacokinetic analysis of tacrolimus early after pediatric liver transplantation. Ther Drug Monit 36: 54-61, 2014.

17. Lu YX, Su QH, Wu KH, Ren YP, Li L, Zhou TY and Lu W: A population pharmacokinetic study of tacrolimus in healthy Chinese volunteers and liver transplant patients. Acta Pharmacol Sin 36: 281-288, 2015.

18. Andreu F, Colom H, Grinyó JM, Torras J, Cruzado JM and Lloberas N: Development of a population PK model of tacrolimus for adaptive dosage control in stable kidney transplant patients. Ther Drug Monit 37: 246-255, 2015.

19. Bergmann TK, Hennig S, Barraclough KA, Isbel NM and Staatz CE: Population pharmacokinetics of tacrolimus in adult kidney transplant patients: Impact of CYP3A5 genotype on starting dose. Ther Drug Monit 36: 62-70, 2014.

20. Han N, Ha S, Yun HY, Kim MG, Min SI, Ha J, Lee JI, Oh JM and Kim IW: Population pharmacokinetic-pharmacogenetic model of tacrolimus in the early period after kidney transplantation. Basic Clin Pharmacol Toxicol 114: 400-406, 2014.

21. Wang DD, Chen X and Li ZP: Wuzhi capsule and haemoglobin influence tacrolimus elimination in paediatric kidney transplantation patients in a population pharmacokinetics analysis: A retrospective study. J Clin Pharm Ther 44: 611-617, 2019.

22. Wang D, Chen X, Xu H and LiZ: Population pharmacokinetics and dosing regimen optimization of tacrolimus in Chinese pediatric hematopoietic stem cell transplantation patients. Xenobiotica: Apr 2, 1-8, 2019 doi: 10.1080/00498254.2019.1601791 (Epub ahead of print). 
23. Wang DD, Chen X, Fu M, Zheng QS, Xu H and Li ZP: Model extrapolation to a real-world dataset: Evaluation of tacrolimus population pharmacokinetics and drug interaction in pediatric liver transplantation patients. Xenobiotica: Jul 3, 1-9, 2019 doi: 10.1080/00498254.2019.1631505 (Epub ahead of print).

24. Wang D, Lu J, Li Q and Li Z: Population pharmacokinetics of tacrolimus in pediatric refractory nephrotic syndrome and a summary of other pediatric disease models. Exp Ther Med 17: 4023-4031, 2019.

25. Anderson BJ and Holford NH: Mechanism-based concepts of size and maturity in pharmacokinetics. Annu Rev Pharmacol Toxicol 48: 303-332, 2008

26. Wang DD, Ye QF, Chen $\mathrm{X}, \mathrm{Xu} \mathrm{H}$ and Li ZP: Population pharmacokinetics and initial dosing regimen optimization of cyclosporin in pediatric hemophagocytic lymphohistiocytosis patients. Xenobiotica: Aug 14, 1-7, 2019 doi: 10.1080/00498254.2019.1651419 (Epub ahead of print).

27. Wang D, Chen X and Li Z: Population pharmacokinetics of sirolimus in pediatric patients with kaposiform hemangioendothelioma: A retrospective study. Oncol Lett 18: 2412-2419, 2019.

28. Sprandel KA, Drusano GL, Hecht DW, Rotschafer JC, Danziger LH and Rodvold KA: Population pharmacokinetic modeling and Monte Carlo simulation of varying doses of intravenous metronidazole. Diagn Microbiol Infect Dis 55: 303-309, 2006.

29. Hahn D, Hodson EM, Willis NS and Craig JC: Corticosteroid therapy for nephrotic syndrome in children. Cochrane Database Syst Rev: CD001533, 2015.

30. Tanaka H, Tsugawa K, Nakahata T, Suzuki K and Ito E: Leukocytapheresis for the treatment of refractory systemic-onset juvenile idiopathic arthritis. Clin Rheumatol 26: 1014-1016, 2007.
31. Kimura Y, Pinho P, Walco G, Higgins G, Hummell D, Szer I, Henrickson M, Watcher S and Reiff A: Etanercept treatment in patients with refractory systemic onset juvenile rheumatoid arthritis. J Rheumatol 32: 935-942, 2005.

32. Quartier P, Taupin P, Bourdeaut F, Lemelle I, Pillet P, Bost M, Sibilia J, Koné-Paut I, Gandon-Laloum S, LeBideau M, et al: Efficacy of etanercept for the treatment of juvenile idiopathic arthritis according to the onset type. Arthritis Rheum 48: 1093-1101, 2003.

33. Mok CC, Tong KH, To CH, Siu YP and Au TC: Tacrolimus for induction therapy of diffuse proliferative lupus nephritis: An open-labeled pilot study. Kidney Int 68: 813-817, 2005.

34. Kauffman RE and Kearns GL: Pharmacokinetic studies in paediatric patients. Clinical and ethical considerations. Clin Pharmacokinet 23: 10-29, 1992.

35. Anderson BJ and Holford NH: Tips and traps analyzing pediatric PK data. Paediatr Anaesth 21: 222-237, 2011.

36. Holford NH: A size standard for pharmacokinetics. Clin Pharmacokinet 30: 329-332, 1996.

37. Savage VM, Deeds EJ and Fontana W: Sizing up allometric scaling theory. PLoS Comput Biol 4: e1000171, 2008.

38. Jacobo-Cabral CO, García-Roca P, Romero-Tejeda EM, Reyes H, Medeiros M, Castañeda-Hernández G and Trocóniz IF: Population pharmacokinetic analysis of tacrolimus in Mexican paediatric renal transplant patients: Role of CYP3A5 genotype and formulation. Br J Clin Pharmacol 80: 630-641, 2015.

This work is licensed under a Creative Commons

Attribution-NonCommercial-NoDerivatives 4.0

International (CC BY-NC-ND 4.0) License. 